\title{
Téoros
}

Revue de recherche en tourisme

\section{Le Sommet mondial de la nordicité à Québec} Du tourisme d'hiver dans le Nord à l'hiver au Groenland

\section{Jan Lundgren}

Volume 18, numéro 2, été 1999

La nordicité

URI : https://id.erudit.org/iderudit/1072104ar

DOI : https://doi.org/10.7202/1072104ar

Aller au sommaire du numéro

Éditeur(s)

Université du Québec à Montréal

ISSN

0712-8657 (imprimé)

1923-2705 (numérique)

Découvrir la revue

Citer cet article

Lundgren, J. (1999). Le Sommet mondial de la nordicité à Québec : du tourisme d'hiver dans le Nord à l'hiver au Groenland. Téoros, 18(2), 43-43.

https://doi.org/10.7202/1072104ar d'utilisation que vous pouvez consulter en ligne.

https://apropos.erudit.org/fr/usagers/politique-dutilisation/ 


\section{LE SOMMET MONDIAL de la nordicité À Québec}

\section{DU TOURISME D'HIVER dANS LE NORD À L'HIVER AU Groenland}

\section{Jan Lundgren}

En plein hiver, plus particulièrement durant la première semaine de février 1999, la ville de Québec a été thôte du Sommet mondial de la nordicité auquel ont participé des représentants des pays circumpolaires et une multitude d'experts dans le domaine de la nordicité. Parmi les thèmes abordés lors du sommet, celui du tourisme a été considérablement représenté. Il en va de soi puisque les territoires circumpolaires situés au nord représenten à bien des égards pour les visiteurs du Sud en quête d'aventures la dernière vraie frontière touristique à franchir. Et de tenir cet événement en hiver en fait une expérience euphorisante pour ceux el celles qui aiment le froid! Les divers articles sur le tourisme qui ont été présentés lors du forum portaient sur un éventail étonnant de sujets: des croisières au large de la côte de Bergen à la Mer de Norvège, des voyages similaires dans le Grand Nord du Québec et un aperçu général de l'avenir du tourisme d'hiver. A ce propos, le réchauffement planétaire en cours pourrait grande. ment désorganiser certaines expériences nordiques de mềme que la vie des peuples autochtones du Nord.

Les discussions avaient tendance à faire références aux grandes étendues de terres émergées de l'Europe et de l'Amérique du Nord, laissant pour compte les destinations touristiques de l'Atlantique Nord qui les séparent et qui font déjà preuve d'un développement touristique dynamique et en plein essor. À cet égard, l'expérience de I'Islande le démontre clairement, le tourisme international ayant connu une croissance accrue durant les vingt dernières années. Que quelques 200000 touristes internationaux visitent annuellement une partie plutôt reculée de l'Atlantique Nord est un indice de l'ampleur de la demande actuelle pour le tourisme et les voyages et du fort potentiel de développement touristique pour les destinations insulaires stratégiquement situées. On peut d'ailleurs citer l'exemple des îles Hawaì qui baignent dans les eaux tropicales du Pacifique et qui illustrent bien les incidences que peut avoir un emplacement avantageusement situé ! Les plus petites îles au nord de l'Écosse et a l'est de la Norvège (les îles Féroé) et les îles Shetland connaissent également une expansion sur le plan touristique, bien que le nombre de visiteurs soit inférieur.

Par ailleurs, il s'avère sensé de considérer les plus vastes terres émergées de l'Arctique, notamment le Groenland, situé de l'autre côté de l'archipel arctique de l'Est du Canada, pour parfaire le portrait touristique de l'Atlantique Nord. Marianne Lykke Thomsen, ministre du Greenland Representation à l'ambassade du Danemark à Ottawa, a brossé un portrait coloré du mode de vie habituel des habitants du Groenland et de son lien avec le développement florissant du tourisme. L'aspect le plus important de son discours visait at expliquer dans quelles mesures les activités hivernales constituent également la base des activités touristiques tout au long de l'année comme c'est le cas, par exemple, des randonnées en traîneaux à chiens et du trekking de longue distance. D'autres attractions plus touristiques ont également été développées au cours des deux dernières années, comme le ski sur les glaciers, la sculpture sur neige et la visite du Igloo Village dont la conception s'inspire du Ice Hotel à Jukkasjarvi en Laponie suédoise. En somme, tout indique qu'un processus de diversification des composantes des attractions touristiques est en cours au Groenland.

Le Groenland a obtenu son autonomie gouvernementale en 1979. Certaines données statistiques démontrent la croissance rapide du tourisme depuis 1992, année durant laquelle le Greenland Tourism (National Tourist Board) a été fondé. Les résultats depuis les sept dernières années sont étonnants en termes de croissance, sinon en nombres absolus : 10000 visiteurs en 1994,16000 en 1997 et 60000 sont attendus d'ici six ans. Il s'agit d'une prévision substantielle qui, pour être rencontrée, exige un développement parallèle des infrastructures en matière de transport et d'hébergement et de la formation en main-d'oeuvre. Tout comme l'Islande qui a réussi à le faire, les habitants de Groenland ont certainement tous les atouts pour y parvenir !

Pour de plus amples renseignements sur le tourisme au Groenland, consultez le site web www,greenland-guide, gl ou le courriel tourism@greennet.gl ou communiquez avec le Greenland Representation à l'ambassade du Danemark à Ottawa (téléphone: (613) 244-2093).

CE TEXTE A ETE TRADUIT DE L'ANGLAIS PAR MANON DUBUC. 